\title{
Avaliaçáo Fisioterapêutica na Síndrome de Potocki-Lupski: Relato de Caso
}

\author{
Physical Therapy Evaluation In Potocki-Lupski Syndrome: A Case Report \\ Angelita de Aguiar', Juliana Cátia de Oliveira², Maria Daniela \\ de Lima e Silva ${ }^{3}$
}

\begin{abstract}
RESUMO
A síndrome de Potocki-Lupski (duplicação 17p11.2 p11.2), reconhecida em 2007, compreende características clínicas como anomalias congênitas, prejuízo intelectual, hipotonia infantil e distúrbio da linguagem. Objetivo. Relatar o caso de uma criança com o diagnóstico clínico de Síndrome de Potocki-Lupski considerando os aspectos de uma avaliação fisioterapêutica. Método. A avaliação fisioterapêutica consistiu na investigação da anamnese, exame físico e avaliação postural. A anamnese foi coletada por meio de um formulário de entrevista semiaberto e o exame físico englobou aspectos respiratórios, neurológicos e musculoesqueléticos. Para caracterizar os desvios posturais foi utilizado o Software de Avaliação Postural (SAPO). Resultados. Criança do sexo masculino, 12 anos, etnia branca, nacionalidade brasileira, apresentou atraso do desenvolvimento motor no início da infância e na aquisição da linguagem. Além disso, apresentou espasticidade em quadríceps e tríceps sural, hiperreflexia patelar e aquiliana, sinal de Babinski e clônus bilateralmente. A análise postural revelou escoliose, anteriorização de cabeça e hipercifose torácica. Consideraçóes finais. Em concordância com os achados científicos, o paciente apresentou alteraçóes posturais, atraso no desenvolvimento e distúrbio da linguagem. Sinais de espectro autista e hipotonia muscular não foram evidenciados em avaliaçáo, embora sejam descritos no quadro clínico desta síndrome. $\mathrm{O}$ exame neurológico revelou sinais de acometimento do trato corticoespinhal.
\end{abstract}

Unitermos. Síndrome, Avaliação, Fisioterapia.

Citação. Aguiar A, Oliveira JC, Silva MDL. Avaliação Fisioterapêutica na Síndrome de Potocki-Lupski: Relato de Caso.

\begin{abstract}
The Potocki-Lupski syndrome (17p11.2 p11.2 duplication), recognized in 2007, comprehends clinical characteristics such as congenital anomalies, intellectual deficit, infantile hypotonia and language disorder. Objective. to describe the case of a child clinically diagnosed with Potocki-Lupski syndrome considering the physical therapeutic evaluation aspects. Method. The physical therapeutic evaluation consisted on the anamnesis investigation, physical examination and postural evaluation. The anamnesis was gathered by means of a semiopen interview form and the physical examination included respiratory, neurologic and musculoskeletal aspects. To characterize the child's postural deviations the Postural Evaluation Software (Software de Avaliação Postural - SAPO) was used. Results. Male, 12 years old, white, Brazilian nationality, presented motor developmental and language acquisition delay. Besides, he presented bilateral quadriceps and triceps surae spasticity, patellar and Achilles tendon hyperreflexia, Babinski sign and clonus. The postural analysis indicated scoliosis, anteriorization of the head and thoracic hyperkyfosis. Final considerations. according to the scientific findings, the patient presented postural alterations, development delay and language disorder. Autistic spectrum and muscular hypotonia were not evidenced in the evaluation, though they are described in the clinical aspects of this syndrome. The neurological examination revealed signs of corticospinal tract impairment.
\end{abstract}

Keywords. Syndrome, Evaluation, Physical Therapy.

Citation. Aguiar A, Oliveira JC, Silva MDL. Physical Therapy Evaluation In Potocki-Lupski Syndrome: A Case Report.
Trabalho realizado na Clínica do Departamento de Fisioterapia da Universidade de Taubaté (UNITAU), Taubaté-SP, Brasil.

1.Fisioterapeuta, Pós-graduanda em Neurologia funcional pela Universidade do Vale do Paraíba, UNIVAP-SP, Professora colaboradora do curso de Fisioterapia da Universidade de Taubaté, UNITAU-SP, Taubaté-SP, Brasil.

2.Fisioterapeuta, Mestre em Distúrbios do Desenvolvimento pela Universidade Presbiteriana Mackenzie-SP, Professora do curso de Fisioterapia da Universidade de Taubaté, UNITAU-SP, Taubaté-SP, Brasil.

3.Fisioterapeuta, Mestre em Ciências Biológicas pela Universidade do Vale do Paraíba, UNIVAP-SP, Professora do curso de Fisioterapia da Universidade de Taubaté, UNITAU, SP, Taubaté-SP, Brasil.
Endereço para correspondência: Maria Daniela de Lima e Silva Avenida Abel Corrêa Guimarães, 132, São Benedito CEP 12420-680, Pindamonhangaba-SP, Brasil.

E-mail: danielalima.s@uol.com.br

Relato de Caso

Recebido em: 23/03/12

Aceito em: 18/03/13

Conflito de interesses: não 


\section{INTRODUÇÃO}

A Síndrome de Potocki-Lupski (SPL), que recebeu essa denominação por ter sido descrita pela primeira vez em abril de 2007 pelos autores Lorraine Potocki e James Lupski, consiste em alteração genética caracterizada pela duplicação na regiáo $17 \mathrm{p} 11.2$, associada com a duplicaçẫo $17 \mathrm{p} 11.2 \mathrm{p} 11.2^{1,2}$.

A duplicação corresponde à repetição de um segmento de um braço cromossômico, podendo o segmento duplicado terminar em uma posição diferente no mesmo cromossomo ou em um cromossomo diferente ${ }^{3}$.

A SPL é uma condição patológica extremamente rara e recentemente reconhecida ${ }^{1}$. Esta síndrome compreende características clínicas como anomalias congênitas, prejuízo intelectual, hipotonia infantil, distúrbio cognitivo e distúrbio da linguagem. Outras alteraçóes frequentes incluem o atraso no desenvolvimento infantil, disfagia orofaríngea, características de autismo, apnéia central do sono, anormalidades no eletroencefalograma (EEG), hipermetropia e anomalias estruturais cardiovasculares ${ }^{1,4}$. Algumas características fenotípicas também podem ser evidenciadas, tais como: rosto triangular, testa larga, micrognatia, microcefalia, hipertelorismo, fendas palpebrais oblíquas e orelhas de implantação baixa. Além disso, uma característica interessante compartilhada pela maioria dos pacientes é um sorriso assimétrico ${ }^{1,5}$.

Ao considerar a variabilidade de características clínicas, sabe-se que diferentes fenótipos podem ser estabelecidos dependendo da dosagem de um gene, ou seja, do número de cópias. Assim sendo, após estudos, evidências mostram que o gene dosagem-sensível denominado RAI1 seja o possível responsável pelas variações fenotípicas do portador da SPL ${ }^{1,6-8}$.

A investigação da SPL em pacientes suspeitos tem como base uma avaliação clínica, cujo exame físico compreende o histórico completo composto por avaliação otorrinolaringológica, oftalmológica e auditiva; testes de desenvolvimento comportamental psiquiátrico; testes para transtorno do espectro autista; ecocardiograma e eletrocardiograma; exame radiográfico das mãos e da coluna vertebral; análise sanguínea; ecografia renal; avaliação do sono, e, por fim, avaliação da fala e da linguagem ${ }^{8}$.

Sendo a SPL uma entidade clínica descoberta recentemente, este estudo objetivou descrever os achados de uma avaliação fisioterapêutica em uma criança com o diagnóstico da síndrome.

\section{MÉTODO}

A pesquisa descritiva do tipo relato de caso foi realizada na clínica do Departamento de Fisioterapia da Universidade de Taubaté- SP (UNITAU), no período de Outubro de 2008 a Novembro de 2009, com aprovação do Comitê de Ética em Pesquisa com seres humanos da Universidade de Taubaté (protocolo 515/08), estado de São Paulo, conforme normas para pesquisa envolvendo seres humanos (Resoluçâo 196/96 do Conselho Nacional de Saúde).

Participou deste estudo criança do sexo masculino, 12 anos de idade, etnia branca, nacionalidade brasileira, com diagnóstico clínico de Síndrome de Potocki-Lupski, atendida no setor de Pediatria da Clínica do Departamento de Fisioterapia da UNITAU.

\section{Procedimento}

A avaliação fisioterapêutica deste estudo foi realizada em três etapas distintas: na primeira, para coleta da anamnese, foi aplicado um formulário de entrevista semiaberto junto à mãe do sujeito a fim de buscar informaçóes importantes para a caracterização do caso clínico em questão, tais como: antecedentes pessoais/familiares, história da gestaçáo e período peri e pós-natal, estágios marcantes do desenvolvimento motor, laudos de exames complementares, presença de patologias associadas, aspectos diagnósticos e clínicos, acompanhamento clínico e terapêutico. Esta entrevista foi gravada para conferir maior fidedignidade às informaçóes obtidas.

$\mathrm{Na}$ segunda etapa, o paciente foi submetido ao exame físico a fim de identificar possíveis alterações respiratórias, neurológicas e musculoesqueléticas. Tal avaliação constou de exames do tônus e força muscular, amplitude de movimento, postura, reaçóes de equilíbrio e proteção, reflexos, sensibilidade, coordenação motora e trocas posturais.

Por fim, na terceira etapa foram obtidas imagens fotográficas do sujeito nas vistas anterior, lateral e posterior, para identificação de desvios do alinhamento postural. Para tanto, foi utilizado o SAPO (Software de Avaliação Postural), que recomenda a demarcação de 
pontos anatômicos no corpo para a avaliação postural por distâncias ou ângulos. Neste estudo, foram utilizadas esferas de isopor com $6 \mathrm{~mm}$ de diâmetro (fixadas ao corpo por fita dupla face) para demarcação dos seguintes pontos anatômicos bilateralmente: trago da orelha externa, acrômio, crista ilíaca ântero-superior (CIAS), crista ilíaca póstero-superior (CIPS), ângulo inferior da escápula, trocânter maior do fêmur, linha articular do joelho, ponto medial da patela, tuberosidade anterior da tíbia, tornozelo sobre o maléolo lateral, tornozelo sobre o maléolo medial, ponto sobre o tendão do calcâneo na altura média dos dois maléolos, calcâneo, ponto entre a cabeça do $2^{\circ}$ e $3^{\circ}$ metatarso, ponto sobre a linha média da perna. Além destes, foram utilizadas as seguintes referências anatômicas para demarcação de pontos na coluna vertebral: proeminência da $2^{\text {a }}$ vértebra cervical, proeminência da $5^{\mathrm{a}}$ vértebra cervical, proeminência da $7^{\text {a }}$ vértebra cervical, proeminência da $1^{\mathrm{a}}$ vértebra torácica, proeminência da $2^{\mathrm{a}}$ vértebra torácica, proeminência da $4^{\mathrm{a}}$ vértebra torácica, proeminência da $6^{\mathrm{a}}$ vértebra torácica, proeminência da $8^{\mathrm{a}}$ vértebra torácica, proeminência da $10^{\mathrm{a}}$ vértebra torácica, proeminência da $12^{\mathrm{a}}$ vértebra torácica, proeminência da $1^{\text {a }}$ vértebra lombar, proeminência da $2^{\text {a }}$ vértebra lombar, proeminência da $3^{a}$ vértebra lombar, proeminência da $4^{\mathrm{a}}$ vértebra lombar, proeminência da $5^{\text {a }}$ vértebra lombar.

Para aquisição das imagens, foi utilizada uma câmera fotográfica digital da marca SONY, modelo CYBER-SHOT DSC (Digital Still Câmera) W150/8.1 megapixels posicionada em um tripé a uma distância de 3 metros do paciente; um fio de prumo profissional para balizar o posicionamento da máquina fotográfica digital; um tapete vermelho $(30$ x $60 \mathrm{~cm})$ usado como marcador para posicionamento dos pés.

Os objetivos, bem como os procedimentos envolvidos nesta pesquisa, foram explicados detalhadamente aos responsáveis pelo sujeito do estudo, os quais assinaram um termo de consentimento livre e esclarecido (TCLE) para a participação no estudo, para o uso de imagens e de informaçóes obtidas pela entrevista.

\section{RESULTADOS}

O diagnóstico clínico de SPL foi estabelecido no ano de 2007, estando a criança com 11 anos, após investigação cromossômica submicroscópica por Microar-
ray-Compative Genomic Hybridization (array-CGH), associada a sinais clínicos apresentados. $\mathrm{O}$ mesmo exame realizado em seus pais, constatou que os mesmos não são portadores da duplicação do cromossomo $17 \mathrm{p} 11.2$, e que, portanto, trata-se de uma mutação nova, não herdada geneticamente.

Informações obtidas através do formulário de entrevista semiaberto não revelaram indícios de consanguinidade entre os pais e nenhum caso de síndrome ou doença neurológica na família. A mãe do paciente revelou tratar-se de seu primeiro filho, negou a ocorrência de abortos, bem como a exposiçáo à radiação e ao uso de medicamentos, drogas, álcool ou tabaco antes ou durante a gestaçấo. A gestação apresentou um período completo de 9 meses, com acompanhamento pré-natal regular a partir do terceiro mês e ausência de qualquer intercorrência durante todo o período gestacional. O parto vaginal transcorreu sem complicaçóes e com apresentação fetal do tipo cefálica. Através do boletim de alta, constatou-se que a criança nasceu com 2.650 gramas, estatura de 47 centímetros, perimetrias cefálica e torácica de 33 e 32 centímetros, respectivamente. $\mathrm{O}$ índice Apgar revelou um escore 07 no $1^{\circ}$ minuto e 08 no $5^{\circ}$ minuto. Apresentou boa sucção ao nascer.

As primeiras alteraçóes foram identificadas aos sete meses de idade com a presença de atraso do desenvolvimento motor e hipotonia. A aquisição da postura sentada sem apoio foi alcançada por volta dos 9 meses de idade, o engatinhar com 11 meses, o ficar de pé com apoio aos doze meses e sem apoio com dezessete meses, a marcha com apoio com dezenove meses e sem apoio com trinta meses. A aquisição de linguagem oral compreensível deu-se por volta de três anos de idade.

Para o exame físico, o paciente compareceu acompanhado da mãe, deambulando sem qualquer apoio ou uso de dispositivo de auxílio à marcha. Apresentou-se colaborativo, comunicativo e obediente aos comandos simples fornecidos pelo terapeuta. Constatou-se ao exame físico, tipo respiratório abdominal com ausência de oclusão labial durante a respiração, amplitude de movimento $(\mathrm{ADM})$ passiva diminuída para a abdução de quadril bilateralmente, dorsiflexão e eversão de tornozelo bilateralmente, extensão de tronco (torácica alta) e inclinação lateral e rotação de tronco bilateralmente. Todos os gru- 
pos musculares apresentaram-se normotróficos. Houve a presença de encurtamentos musculares bilaterais de flexores de joelho, plantiflexores e inversores de tornozelo.

$\mathrm{Na}$ avaliação do tônus muscular, realizada através do estiramento passivo da musculatura, obteve-se $1+$, segundo a Escala de Ashworth modificada (1964), caracterizando hipertonia muscular do tipo elástica (espasticidade) em flexores plantares de tornozelo bilateralmente e extensores de joelho bilateralmente. $\mathrm{O}$ teste para o reflexo cutâneo plantar evidenciou resposta em extensão caracterizando o sinal de Babinski bilateralmente, enquanto os reflexos ósteo-tendíneos patelar e aquileu revelaram hiperreflexia com aumento da área reflexógena bilateralmente. Houve a presença de clônus esgotável na região de tornozelo bilateralmente. Segundo o teste de força muscular manual ${ }^{9}$, obteve-se grau 4 de força muscular para flexores e extensores de punho, flexores e extensores da articulação metacarpo-falangeana, flexores e extensores de dedos, dorsiflexores e eversores de tornozelo, todos bilateralmente; e grau 3 para adutores e abdutores de dedos bilateralmente. Os demais grupos musculares obtiveram grau 5 de força muscular.

Para melhor caracterizar as alteraçóes posturais evidenciadas ao exame físico, realizou-se a análise dos ângulos utilizando-se o SAPO. A descrição e interpretaçâo das variáveis analisadas encontram-se na Tabela 1 , enquanto os resultados dos ângulos obtidos encontram-se ilustrados na Tabela 2. Observou-se na vista anterior (Figura 1), que o ângulo H_AC (alinhamento horizontal dos acrômios) revelou uma leve tendência de depressão do acrômio à direita. Da mesma forma, o ângulo H_EIAS (alinhamento horizontal das espinhas ilíacas ântero-superiores) mostrou que a pelve direita encontrou-se mais elevada em relação à pelve esquerda, ao passo que, o ângulo AC_EIAS (alinhamento entre os dois acrômios e as duas espinhas ilíacas ântero-superiores) indicou que a distância entre o acrômio e a EIAS direita apresentou-se menor em relação ao lado esquerdo, demonstrando uma inclinação lateral de tronco à direita. Abordando a vista lateral esquerda (Figura 2) e levando em conta os ângulos H_CA_L (alinhamento horizontal da cabeça na vista lateral) e V_CA_L (alinhamento vertical da cabeça na vista lateral), foi possível constatar uma anteriorização de cabeça. Ainda na vista lateral, enquanto que o ângulo
CT (cifose torácica) caracterizou um aumento da cifose torácica fisiológica, o ângulo LL identificou uma leve retificação da coluna lombar. Por fim, o Centro de Gravidade mostrou-se projetado para anterior e desviado para a esquerda.

Tabela 1

Descrição e interpretação das variáveis analisadas no estudo conforme o Software de avaliação postural (SAPO)

\begin{tabular}{|c|c|c|}
\hline Variável & Siglas & Determinaçáo do ângulo \\
\hline $\begin{array}{l}\text { Alinhamento } \\
\text { horizontal dos } \\
\text { acrômios (graus) }\end{array}$ & H_AC & $\begin{array}{l}\text { Ângulo determinado entre a reta } \\
\text { formada com os pontos marcados } \\
\text { nos acrômios em relação a uma reta } \\
\text { horizontal. }\end{array}$ \\
\hline $\begin{array}{l}\text { Alinhamento } \\
\text { horizontal das EIAS } \\
\text { (graus) }\end{array}$ & H_EIAS & $\begin{array}{l}\text { Ângulo determinado entre a reta } \\
\text { formada com os pontos marcados } \\
\text { nas EIAS em relaçáo a uma reta } \\
\text { horizontal. }\end{array}$ \\
\hline $\begin{array}{l}\text { Alinhamento entre } \\
\text { os dois acrômios e as } \\
\text { duas EIAS (graus) }\end{array}$ & AC_EIAS & $\begin{array}{l}\text { Ângulo entre os dois acrômios e } \\
\text { as duas espinhas ilíacas ântero- } \\
\text {-superiores. }\end{array}$ \\
\hline $\begin{array}{l}\text { Alinhamento } \\
\text { horizontal da cabeça } \\
\text { na vista lateral (graus) }\end{array}$ & H_CA_L & $\begin{array}{l}\text { Ângulo entre a reta definida pelos } \\
\text { pontos marcados no trago e } \mathrm{C} 7 \mathrm{em} \\
\text { relação a uma reta horizontal. }\end{array}$ \\
\hline $\begin{array}{l}\text { Alinhamento vertical } \\
\text { da cabeça na vista } \\
\text { lateral (graus) }\end{array}$ & V_CA_L & $\begin{array}{l}\text { Ângulo entre a reta formada pelos } \\
\text { pontos marcados no trago e no acrô- } \\
\text { mio em relaçáo a uma reta vertical. }\end{array}$ \\
\hline Cifose torácica & CT & Pontos de referência T1, T7 e T12. \\
\hline Lordose lombar & LL & Pontos de referência T12, L3 e L5. \\
\hline $\begin{array}{l}\text { Centro de gravidade } \\
\text { (CG) (\%) }\end{array}$ & CG & $\begin{array}{l}\text { A estimativa da posição do CG é } \\
\text { calculada pelo SAPO, utilizando-se } \\
\text { de pontos específicos demarcados } \\
\text { no indivíduo. A projeçãa do CG é } \\
\text { mostrada em relação à base de su- } \\
\text { porte tendo como origem a projeçáo } \\
\text { da posição média entre os maléolos } \\
\text { laterais. }\end{array}$ \\
\hline
\end{tabular}

Variáveis obtidas através da marcação de pontos anatômicos para identificação de assimetria postural.

Tabela 2

Resultados das variáveis analisadas pelo SAPO

\begin{tabular}{cc}
\hline Variável & Ângulos obtidos \\
\hline H_AC & $-1^{\circ}$ \\
H_EIAS & $-6.1^{\circ}$ \\
AC_EIAS & $5.1^{\circ}$ \\
H_CA_L & $46.7^{\circ}$ \\
V_CA_L & $5.9^{\circ}$ \\
CT & $146^{\circ}$ \\
LL & $184.7^{\circ}$ \\
\hline
\end{tabular}

Assimetria no plano frontal: valores positivos representam o CG desviado para a direita, enquanto valores negativos representam o CG desviado para a esquerda. Assimetria no plano sagital: valores positivos representam o CG desviado para anterior, enquanto valores negativos representam o CG desviado para posterior. 
Figura 1. Pontos anatômicos para identificação de assimetria postural na vista anterior. Imagem utilizada com autorizaçáo do responsável pelo paciente.

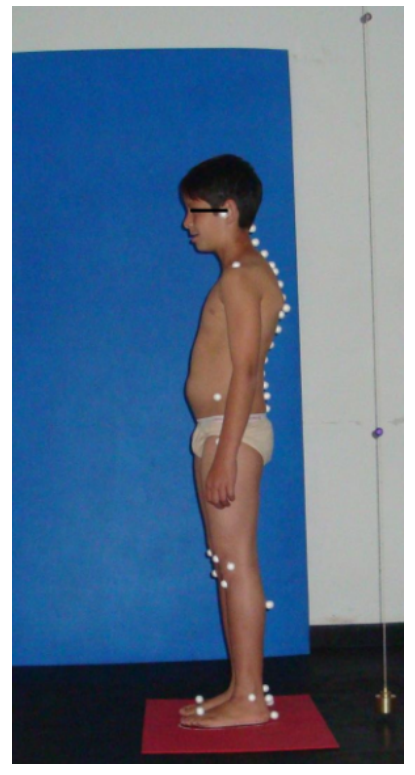

Figura 2. Pontos anatômicos para identificação de assimetria postural na vista lateral. Imagem utilizada com autorização do responsável pelo paciente.

\section{DISCUSSÃO}

A Síndrome de Potocki-Lupski, um raro transtorno genético caracterizado pela duplicação em uma parte do braço curto do cromossomo 17, compreende diversas manifestações clínicas e dentre elas o atraso no desenvolvimento infantil ${ }^{1}$.

Foi constatada neste relato, através da anamnese, a presença de atraso do desenvolvimento apenas nos estágios iniciais do desenvolvimento, pressupondo-se, desta forma, que as informaçóes ambientais auxiliaram no processo de aprendizagem motora ${ }^{10}$.

Ao considerar que o desenvolvimento humano abrange a participação e integridade de diferentes áreas e sistemas, é importante relevar o desenvolvimento da linguagem e psíquico. Sob este aspecto, em concordância com Potocki ${ }^{1}$, a pesquisa verificou que o paciente relatado também apresentou atraso na aquisição da linguagem, pobre vocabulário, fala infantilizada e prejuízos na articulação de palavras, conforme relatório do profissional responsável.

Estudo recente aponta de forma relevante a presença de prejuízo intelectual e distúrbios do comportamento incluindo atipicidade, ansiedade e falta de atenção ${ }^{5}$.

No caso apresentado, foi relevante a ausência de hipotonia ao exame físico. Adversamente, constatou-se hipertonia elástica, acompanhada de hiperreflexia, Babinski e clônus, manifestações decorrentes de lesão do sistema nervoso central ${ }^{11}$.

No entanto, tendo em vista tratar-se de uma síndrome pouco descrita na literatura científica, supõe-se que o quadro sintomatológico da mesma esteja em processo de investigação e análise pormenorizada. Tal processo dependerá de novos diagnósticos estabelecidos. Portanto, não se sabe se outros sintomas, além dos já descritos hoje, servirão para compor clinicamente esta doença e delinear os aspectos patognomônicos da mesma.

Em concordância com alguns estudos ${ }^{1,7,12}$ que citaram alteraçôes posturais no quadro clínico que acompanha a patologia, como hipercifose torácica e desvios das curvaturas da coluna vertebral (escolioses) ${ }^{12}$, este relato permitiu identificar outras alteraçóes posturais associadas.

Para servir de complemento à análise postural computadorizada, o sujeito foi submetido à realização de exame radiográfico da coluna vertebral, o qual não evidenciou qualquer alteração da integridade ósteo-articular.

Sabe-se, contudo, que muitas alteraçóes posturais são evidenciadas ao exame clínico (avaliação postural) não havendo correlação direta com os resultados encontrados ao raio- $\mathrm{x}^{13}$.

Segundo Potocki ${ }^{1}$ a dosagem de um gene, ou seja, do número de cópias, determina diferentes fenótipos e manifestações clínicas. Após estudos ${ }^{4,6,7}$, evidências mostram que o gene dosagem-sensível denominado RAI1 seja o possível responsável pelas variaçóes fenotípicas que conferem ao portador da SPL características autísticas, assim como as demais características ${ }^{4,6,7}$.

Tal abordagem parece justificar a variabilidade clí- 
nica adversa presente neste caso clínico quando comparado às constataçóes realizadas pela literatura científica ${ }^{1,2,5-7}$ até o presente momento.

\section{CONSIDERAÇÕES FINAIS}

A Síndrome de Potocki-Lupski (duplicação de parte do braço curto do cromossomo 17) é uma condiçấo genética recentemente descoberta que acarreta atraso do desenvolvimento infantil, espectro autista, apneia do sono, prejuízo intelectual e comportamental, dentre outras características.

Este relato de caso expôs características da SPL evidenciadas em uma avaliação fisioterapêutica, tais como atraso do desenvolvimento no início da infância e alteraçóes da postura como hipercifose e escoliose.

Em virtude da escassez literária, sugere-se a realização de estudos mais abrangentes, a fim de explorar um maior número de alterações físicas, psíquicas e comportamentais que sirvam para uma melhor caracterização do quadro clínico da doença.

\section{AGRADECIMENTOS}

Agradecemos ao paciente e a sua mãe, que concordaram em participar do estudo, à Profa Dra. Ana Cristina Gobbo César e à Profa Msc. Alex Sandra Oliveira de Cerqueira, que auxiliaram na realização desta pesquisa.

\section{REFERÊNCIAS}

1.Potocki L, Bi W, Treadwell-Deering D, Carvalho CM, Eifert A, Friedman EM, et al. Characterization of Potocki-Lupski Syndrome (dup (17) (p11.2 p11.2)) and delineation of dosage-sensitive critical interval that can convey an autism phenotype. Am J Hum Genet 2007;80:633-49.

http://dx.doi.org/10.1086/512864

2.Zhang F, Potocki L, Sampsom JB, Liu P, Sanchez-Valle A, Robbins-Furman $\mathrm{P}$, et al. Identification of uncommon recurrent Potocki-Lupski syndrome- asso- ciated duplication and the distribution of rearrangement types and mechanisms in PTLS. Am J Hum Geneti 2010;86:462-70.

http://dx.doi.org/10.1016/j.ajhg.2010.02.001

3.Griffiths AJF, Gelbart W, Miller JH, Lewontin RC. Mudanças cromossômicas em larga escala. In: Jorde LB, Suzuki DT, Gelbart W. Genética médica. 2nd. ed. Rio de Janeiro: Guanabara Koogan; 2000, p 477.

4.Potocki L, Chen KS, Koeuth T, Iannaccone ST, Shapira SK, Kashork CD, et al. DNA rearrangements on both homologues of chromosome 17 in a mildly delayed individual with a family history of autosomal dominant carpal tunnel syndrome. Am J Hum Genet 1999;64:471-8.

http://dx.doi.org/10.1086/302240

5.Treadwell-Deering DE, Powell MP, Potocki L. Cognitive and Behavioral Characterization of the Potocki-Lupski Syndrome (Duplication 17p11.2). J Dev Behav Pediatr 2010;31:137-43.

http://dx.doi.org/10.1097/DBP.0b013e3181cda67e

6.Bi W, Yan J, Shi X, Yuva-Paylor LA, Antalffy BA, Goldman A, et al. Rai1 deficiency in mice causes learning impairment and motor dysfunction, whereas Rail heterozygous mice display minimal behavioral phenotypes. Hum Mol Genet 2007;16:1802-13.

http://dx.doi.org/10.1093/hmg/ddm128

7.Molina J, Carmona-Mora P, Chrast J, Krall PM, Canales CP, Lupski JR, et al. Abnormal social behaviors and altered gene expression rates in a mouse model for Potocki-Lupski syndrome. Human Molecular Genetic 2008;17:2486-95. http://dx.doi.org/10.1093/hmg/ddn148

8.Departament of Molecular and Human Genetics (Endereço na Internet). Texas: BCM Baylor College of Medicine. Houston. (atualização 01/2010; citado em 11/2010). Disponível em: http://www.bcm.edu/genetics/potocki_lupski/ index.cfm

9.Kandell FP, McCreary EK, Provance, PG. Muscle testing and function. 4th. ed. São Paulo: Manole; 1994, p.185-9.

10.Flehmig I. Evolução normal da motricidade e suas variaçóes. In: Holle B. Texto e Atlas do desenvolvimento normal e seus desvios no lactente: diagnóstico e tratamento do nascimento até o $18^{\circ}$ mês. 2nd. ed. Rio de Janeiro: Atheneu; 2002. p.3-11.

11.Mutarelli GE. Propedêutica neurológica: do sintoma ao diagnóstico. 5th. ed. São Paulo: Sarvier; 2000, p.7-24.

12.Martin J, Knight SJ, Sharp AJ, Eichler EE, Hurst J, Kini U. Potocki-Lupski syndrome mimicking a connective tissue disorder. Clinical dysmorphology. 2008; 17:211-3.

http://dx.doi.org/10.1097/MCD.0b013e328303b9c2

13.Mangueira JO. Prevalência de desvios na coluna vertebral ao exame físico EME estudantes de 11 a 16 anos em uma escola do bairro Sinhá Sabóia (Monografia). Sobral-CE: Universidade Estadual Vale do Aracajú, 2004, 67p. 14.Ribeiro EC, Marchiorin SC, Silva AMT. Electromyographic muscle EMG activity in mouth and nasal breathing children. J Craniomandibular Prat 2004:22:145-50.

15.Felicio CM. Fonoaudiologia aplicada a casos odontológicos: motricidade oral e audiologia. 1. ed. São Paulo: Pancast, 1999, p.174-75. 